DOI https://doi.org/10.36059/978-966-397-130-8/167-174

\title{
PRE-SERVICE PRIMARY SCHOOL TEACHERS' PERSONAL SELF-EFFICACY DEVELOPING: THE CONCEPT, MECHANISM AND SOURCES
}

\section{Martyniuk A. P.}

\section{INTRODUCTION}

Nowadays Elementary teacher education in Ukraine has been facing the dilemma of cultivating prospective teachers to be generalists or specialists for certain subject areas. Referring to the significant factors affecting teacher education, "teacher efficacy" deserves to be in the heart of this dilemmatic evolution.

Founded in social cognitive theory of Albert Bandura ${ }^{1}$, teachers' selfefficacy beliefs have been repeatedly associated with positive teaching behaviours and student outcomes. However, teacher efficacy has developed a storied history regarding construct validity and measurement integrity. Study of teacher efficacy now stands on the verge of maturity, but such developmental growth will likely be contingent on development of strong theoretical models and effective instrumentation to assess theoretical constructs.

The purpose of the present article is to: briefly review the theoretical foundation of pre-service primary teacher efficacy and discuss important substantive implications stemming from efficacy research that may advance the field of teachers' professional education.

The theoretical foundation of self-efficacy is found in social cognitive theory, developed by current Stanford professor Albert Bandura (1977, 1997). Central to Bandura's (1997) framework is his concept of selfefficacy. Bandura's aspirations about self-efficacy were grand, as reflected in the title of his 1977 article "Self-Efficacy:

Toward a Unifying Theory of Behavioral Change." In this seminal work, Bandura defined self-efficacy as "beliefs in one's capabilities to

\footnotetext{
${ }^{1}$ Bandura, A. (2001). Social cognitive theory: An agentic perspective. Annual Review Psychology, 52, p. 1-26.
} 
organize and execute the courses of action required to produce given attainments"

Bandura (1997) proposed that because self-efficacy beliefs were explicitly self-referent in nature and directed toward perceived abilities given specific tasks, they were powerful predictors of behaviour. The research literature has supported this proposition. Research has linked efficacy to a variety of clinical issues such as phobias (Bandura, 1983), addiction (Marlatt, Baer, \& Quigley, 1995), depression (Davis \& Yates, 1982), and smoking behaviour (Garcia, Schmitz, \& Doerfler, 1990). Educationally, self-efficacy beliefs are related to academic performance and self-regulated learning (cf. Hackett, 1995; Pajares, 1996; Schunk, 1991; Zimmerman, 1995).

Although a number of studies have investigated self-efficacy in different subject matters, little research has been conducted to explore the perceived efficacy of pre-service primary school teachers.

Understanding teachers' perceptions and beliefs is important because teachers, heavily involved in various teaching and learning processes, are practitioners of educational principles and theories (Jia, Eslami \& Burlbaw, 2006). Teachers have a primary role in determining what is needed or what would work best with their students. Findings from research on teachers' perceptions and beliefs indicate that these perceptions and beliefs not only have considerable influence on their instructional practices and classroom behaviour but also are related to their students' achievement. ${ }^{3}$

Thus, knowing the perceptions and beliefs of teachers enables one to make predictions about teaching and assessment practices in classrooms.

Teachers' beliefs about their own effectiveness, known as teacher efficacy, underlie many important instructional decisions which ultimately shape students' educational experiences. Teacher efficacy is believed to be strongly linked to teaching practices and student learning outcomes.

The task of creating environments conductive to learning rests heavily on the talents and self-efficacy of teachers. Evidence indicates that classroom atmospheres are partly determined by teachers' beliefs in their instructional efficacy.

\footnotetext{
${ }^{2}$ Bandura, A. (1977). Self-efficacy: Toward a unifying theory of behavior change. Psychological Review, 84, $19 \backslash 215$.

${ }^{3}$ Soodak, L. C. \& Podell, D. M. (1997). Efficacy and experience: perceptions of efficacy among preservice and practicing teachers. Journal of Research and Development in Education, 30, p. 214-221.
} 
The literature widely documents the pervasive influence of selfefficacy beliefs and corroborates social cognitive theory that places these beliefs at the roots of human agency (Bandura, 2001).

Elementary Teachers' sense of efficacy can potentially influence both the kind of environment that they create as well as the various instructional practices introduced in the classroom (Bandura, 1997). Furthermore, teachers with a high sense of self-efficacy are confident that even the most difficult students can be reached if they exert extra effort; teachers with lower self-efficacy, on the other hand, feel a sense of helplessness when it comes to dealing with difficult and unmotivated students (Gibson \& Dembo, 1984). Gibson and Dembo found that teachers, who have a high sense of instructional efficacy devote more classroom time to academic learning, provide students who have difficulty learning with the help they need to succeed, and praise them for their accomplishments. In contrast, teachers who have a low sense of instructional efficacy spend more time on non-academic pastimes, readily give up on students if they do not get quick results, and criticize them for their failures. Thus, teachers who believe strongly in their instructional efficacy create mastery experiences for their students. Those beset by self-doubts construct classroom environments that are likely to undermine students' sense of efficacy and cognitive development ${ }^{4}$.

As Woolfolk and Hoy reported, teachers' sense of personal efficacy affects their orientation toward the educational process as well as their specific instructional practices 5 . Those who have a low sense of instructional efficacy favour a custodial orientation that relies heavily on extrinsic inducements and negative sanctions to get students to study. Teachers who believe strongly in their instructional efficacy support development of students' intrinsic interests and academic self-directedness.

Yilmaz-Tuzun (2008) examined in a study pre-service teachers' beliefs about different teaching methods (e.g., inquiry, concept map), classroom management (e.g., how to handle off-task students, discipline), the use of different assessment strategies (e.g., portfolio, structured test) and content knowledge (e.g., biology, chemistry). The author's study suggests that the better teacher's knowledge about content, the easier it will

\footnotetext{
${ }^{4}$ Gibson, S., \& Dembo, M. (1984). Teacher efficacy: Aconstructvalidation. Journal of Educational Psychology, 76, 569-582.

5 Tschannen-Moran, M. \& Woolfolk Hoy, A. (2001). Teacher efficacy: Capturing an elusive construct. Teaching and Teacher Education, 17, p. 783-805.
} 
be for them to select appropriate teaching methods and pedagogical activities.

We consider that teacher self-efficacy is the belief that one is capable of exercising personal control over one's behaviour, thinking, and emotions. Effective teachers believe that they can make a difference in children's lives, and they teach in ways that demonstrate this belief. What teachers believe about their capability is a strong predictor of teacher effectiveness. People who hold strong self-efficacy beliefs tend:

- to be more satisfied with their job;

- to demonstrate more commitment;

- to have lower absenteeism.

Teachers, who have high self-efficacy, tend:

- to persist in failure situations;

- to take more risks with the curriculum;

- to use new teaching approaches;

- to get better gains in children's achievement;

- to have more motivated students.

Figure 1 presents a model which attempts to illustrate how selfefficacy as a teacher, and teacher outcome expectations relate to action. Five assumptions underpin this model, all of which are supported by research findings: 


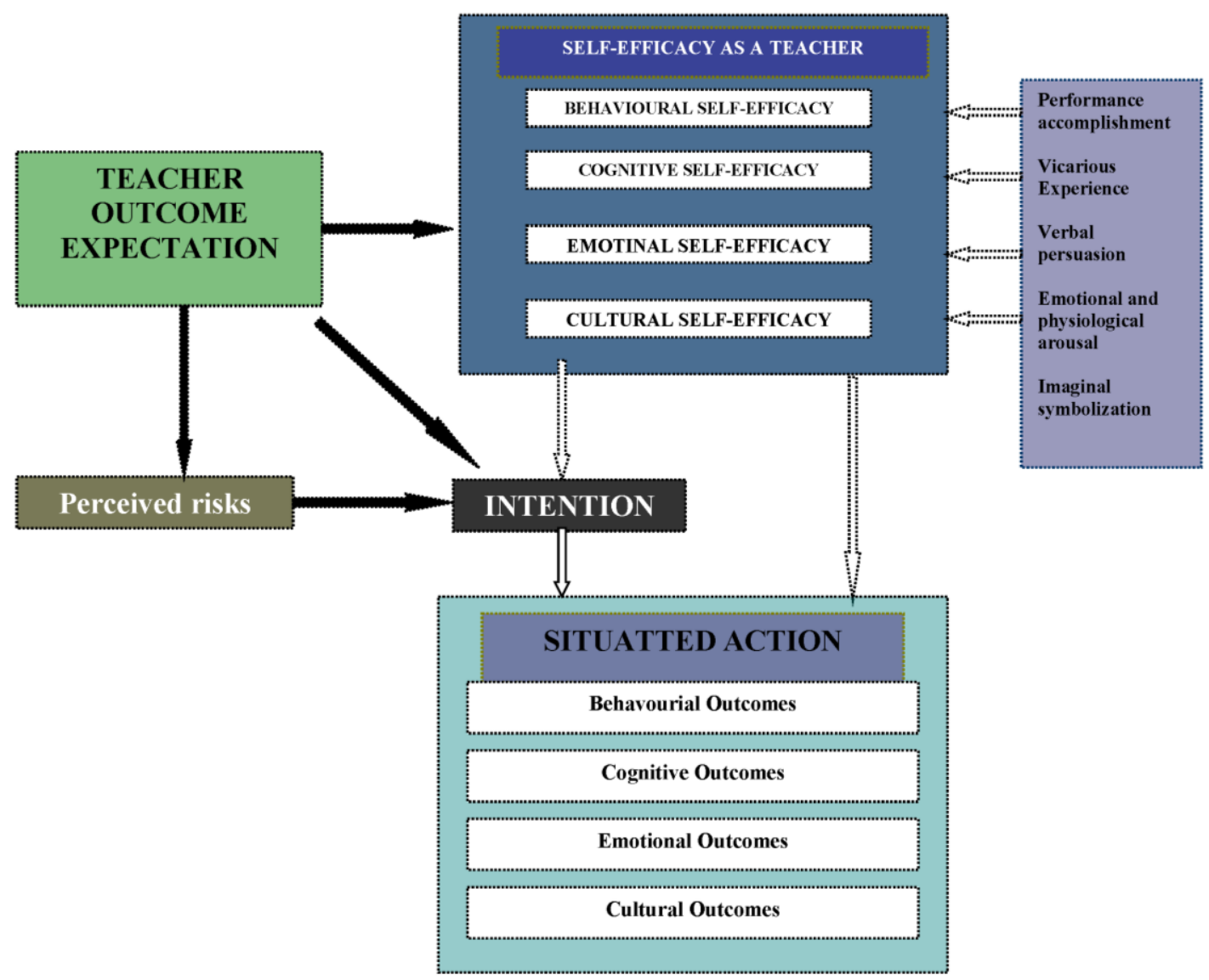

Fig. 1: The relationship between teacher outcome expectations, self efficacy as a teacher, and teacher action (Gibbs, C. J.) ${ }^{6}$

1. Self-reflection. Good teaching is not the mere carrying out techniques' tasks. Effective teachers reflect on their own thinking and about their actions. Teachers need to be capable of self-reflection.

2. Intentional Behaviour. Much of teachers' behaviour is purposeful, intentional, and goal-directed. Teachers' behaviour is guided by forethought (including anticipation and prediction).

3. Symbolic Representation. How teachers intend to teach depends, in part, on their capacity for symbolic representation. Symbolic representation creates internal representations of experience, generates innovative and multiple solutions, and characterizes possible consequences (behavioural, cognitive, emotional) of applying these solutions.

\footnotetext{
${ }^{6}$ Gibbs, C.J. (2000, August). Self-efficacious teachers: New directions in the reconstruction of teacher education. Professorial Lecture, Auckland University of Technology.
} 
4. Self-Regulation. Teachers require the capacity to self-regulate their thinking, behaviour, and emotions. They need to be able to exercise direct control over their thinking, behaviour, and teaching circumstances. Teachers might be said to be self-regulated when they are metacognitively, motivationally, and behaviourally active participants in the process of teaching (see Zimmerman, 1986).

5. Triadic Reciprocal Causation. To understand effective teachers, we need to acknowledge that teachers' actions do not occur in vacuums. There is an interaction, reciprocity, and inter-dependence of teachers' inner personal factors (cognition, emotion, biological events), teachers' behaviour, and the circumstances in which this teaching occurs. Bandura (1989) refers to this as triadic reciprocal causation.

There are at least four kinds of self-efficacy as a teacher, each of which is instrumental in explaining how teachers teach and their willingness to persist even when the odds appear to be stacked against them (Gibbs, 2000). As such, they are important indicators of teacher effectiveness.

\section{Behavioural Self-Efficacy as a Teacher}

Behavioural self-efficacy as a teacher is the self-belief in one's capability as a teacher to perform specific actions to deal with specific teaching situations.

\section{Cognitive Self-Efficacy as a Teacher}

Cognitive self-efficacy as a teacher is the self-belief in one's capability as a teacher to exercise control over one's thinking in specific teaching situations.

\section{Emotional Self-Efficacy as a Teacher}

Emotional self-efficacy as a teacher is the self-belief in one's capability as a teacher to exercise control over one's emotions in specific teaching situations.

\section{Cultural Self-Efficacy as a Teacher}

Cultural self-efficacy as a teacher is the self-belief in one's capability as a teacher to perform specific actions in culturally-appropriate ways in specific teaching situations. This construct remains relatively unresearched.

These four kinds of self-efficacy as a teacher interact. Further, these self-efficacy beliefs are neither necessarily mutually exclusive nor independent. An effective teacher usually has a strong belief in her 
capability to exercise control over her emotions, behaviour, and thinking, and is secure in her beliefs about her capacity to teach effectively in culturally appropriate ways. The purpose of teacher education is to assist student teachers understand, explain and use self-efficacy to mediate what they know and can do, and how they teach.

\section{CONCLUSIONS}

On the basis of the data analyzed, the results suggest the following aspects of interest. First, teacher self-efficacy beliefs positively influence students' learning experiences and academic outcomes. Moreover, preservice teachers who had higher efficacy and used time and study environment management strategies exerted more effort than those with lower efficacy.

It is conceivable that the successful implementation of teacher's education programs may depend on teachers' self-efficacy beliefs, that is, their personal beliefs regarding their ability to teach and their ability to produce positive outcomes in for students. Therefore, efficacy beliefs give a measure of the sense of how the preservice teachers perceived their strengths and preparedness as potential teachers. Due to the vital role preservice teachers will play in educating younger generation, teacher education programs need to evaluate efficacy levels of their teacher education students and begin to find ways to enhance their efficacy beliefs regarding teaching. Then these teacher education programs can begin to launch future teachers who are ready, willing, and able to meet the needs of their students.

\section{SUMMARY}

The article is devoted to the pre-service primary school teachers' personal self-efficacy developing. On the basis of the data analysed, the results suggest the following aspects of interest. First, teacher self-efficacy beliefs positively influence students' learning experiences and academic outcomes. Moreover, pre-service teachers who had higher efficacy and used time and study environment management strategies exerted more effort than those with lower efficacy.

It is conceivable that the successful implementation of teacher's education programs may depend on teachers' self-efficacy beliefs, that is, their personal beliefs regarding their ability to teach and their ability to 
produce positive outcomes in for students. Therefore, efficacy beliefs give a measure of the sense of how the preservice teachers perceived their strengths and preparedness as potential teachers. Due to the vital role preservice teachers will play in educating younger generation, teacher education programs need to evaluate efficacy levels of their teacher education students and begin to find ways to enhance their efficacy beliefs regarding teaching. Then these teacher education programs can begin to launch future teachers who are ready, willing, and able to meet the needs of their students.

\section{REFERENCES}

1. Gibson, S., \& Dembo, M. (1984). Teacher efficacy: A construct validation. Journal of Educational Psychology, 76, 569-582.

2. McDonald, T., \& Siegall, M. (1993). The effects of technological self-efficacy and job focus on job performance, attitudes, and withdrawal behaviors. Journal of Psychology, 5, p. 465-475.

3. Multon, K. D., Brown, S. D., \& Lent, R. W. (1991). Relation of self-efficacy beliefs to academic outcomes: A meta-analytic investigation. Journal of Counseling Psychology, 38, p. 30-38.

4. Trentham, L., Silvern, S., \& Brogdon, R., (1985). Teacher efficacy and teacher competency ratings. Psychology in the Schools, 22 (3), p. 343-352.

5. Tschannen-Moran, M. \& Woolfolk Hoy, A. (2001). Teacher efficacy: Capturing an elusive construct. Teaching and Teacher Education, 17 , p. 783-805.

\section{Information about the author: \\ Martyniuk A. P.}

Candidate of Pedagogical Sciences, Associate Professor, Head of the Department of Ukrainian and Foreign Philology, Lutsk National Technical University 75 Lvivska str., Lutsk, Volyn region, 43000, Ukraine 